- Work describes widespread microbial contamination of dental unit water lines which appears unrelated to age and make of unit.

- Recommendations use of sterile irrigants for surgical procedures.

- Suggests that units should be redesigned to reduce build up of biofilm.

\title{
A cross sectional study of water quality from dental unit water lines in dental practices in the West of Scotland
}

\author{
A. J. Smith, ${ }^{1}$ S. McHugh, ${ }^{2}$ L. McCormick, ${ }_{1}^{3}$ R. Stansfield, ${ }_{1}^{4}$ A. McMillan ${ }^{5}$ and J. $\operatorname{Hood}^{6}$
}

\begin{abstract}
Objective To determine the microbiological quality of water from dental units in a general practice setting and current practice for disinfection of units.
\end{abstract}

Design A cross-sectional study of the water quality from 40 dental units in 39 general practices and a questionnaire of the disinfection protocols used in those practices.

Setting NHS practices in primary dental care.

Subjects Thirty-nine general practices from the West of Scotland. Methods Water samples were collected on two separate occasions from dental units and analysed for microbiological quality by the total viable count (TVC) method. Water specimens were collected from the triple syringe, high speed outlet, cup filler and surgery tap. Each participating practitioner was asked to complete a questionnaire.

Results Microbial contamination was highest from the high speed outlet followed by the triple syringe and cup filler. On average, the TVC counts from the high speed water lines at $37^{\circ} \mathrm{C}$ and for the high speed lines, triple syringe and cup filler at $22^{\circ} \mathrm{C}$ were significantly higher than that from the control tap water specimens. The study included units from 11 different manufacturers with ages ranging from under one year to over eight years. The age of the dental unit analysed did not appear to influence the level of microbial contamination. Five of the practices surveyed used disinfectants to clean the dental units but these had no significant effect on the microbiological quality of the water. The majority of dental units ( 25 out of 40) were never flushed with water between patients. A number of different non-sterile irrigants were used for surgical procedures.

Conclusion The microbiological quality of water from dental units in general dental practice is poor compared with that from drinking water sources. Suitable sterile irrigants should be used for surgical procedures in dental practice. Further work is required for pragmatic decontamination regimens of dental unit water lines in a general dental practice setting

Senior Lecturer, Infection Research Group, Glasgow Dental Hospital \& School ${ }^{2}$ Statistician, Infection Research Group, Glasgow Dental Hospital \& School, $3,4,5$ General Dental Practitioner, Orchard Park Dental Practice, 124 Main Street, Thornliebank, Glasgow, ${ }^{6}$ Consultant Microbiologist, Bacteriology Department, Glasgow Royal Infirmary, Castle Street, Glasgow.

*Correspondence to: Andrew J. Smith, Infection Research Group, Glasgow Dental Hospital \&t School, 378 Sauchiehall Street, Glasgow G2 3JZ

Email:a.smith@dental.gla.ac.uk

\section{Refereed paper}

Received 11.03.02; Accepted 16.07.02

() British Dental Journal 2002; 192: 645-648

\section{INTRODUCTION}

It was reported as early as 1963 that water from dental lines can be heavily contaminated with micro-organisms ${ }^{1}$ and this has been confirmed more recently. ${ }^{2-7}$ The source of bacterial contamination within the dental unit water supply is thought to be due to microcolonies of proliferating micro-organisms on the inner surface of the water lines. The organisms are embedded in a matrix of extra-cellular polymeric substances forming a biofilm. Bio-films are important because they protect organisms from the effects of heat and chemicals thus reducing their susceptibility to disinfection processes. Little has been published on the microbiological quality of water from general dental practice in the UK. The water quality regulations provide a legal definition of the term 'wholesomeness' when applied to potable water (mains water that is supplied for consumption) and include a number of chemical and microbiological parameters. ${ }^{8}$ Waterborne pathogens such as faecal coliforms, for example Escherichia coli, should always be absent from potable water supplies. The usual guideline for the number of colony forming units (cfu) accepted in potable water is less than $10 \mathrm{cfu} / \mathrm{ml}$ at $37^{\circ} \mathrm{C}$ (or less than $100 \mathrm{cfu} / \mathrm{ml}$ at $22^{\circ} \mathrm{C}$ ). ${ }^{8}$ Since the fine spray produced during treatment is probably inhaled by both the patient and the dental staff and almost certainly swallowed by the patient, these guidelines were interpreted as the standard desired for water emerging from dental units.

Numerous methods have been suggested to combat the problem of microbial contamination of dental unit water supplies. The British Dental Association (BDA) ${ }^{19}$ and Centers for Disease Control $(\mathrm{CDC})^{20}$ recommend that all water lines should be allowed to run and discharge water for several minutes at the beginning of each day and for a shorter interval between patient appointments.

We report a study of the microbiological quality of the water supply from 40 dental units in general dental practice and the results of a questionnaire from those practices surveyed on their current disinfection protocols to reduce microbial contamination in the water lines.

\section{MATERIALS AND METHODS}

General dental practices working in the National Health System in the Greater Glasgow Health Board area were telephoned and invited to participate in the study. Water samples of between 10- 
$50 \mathrm{~mL}$ were obtained from the three sources of water in a dental unit, namely the triple syringe, high speed handpiece and cup filler. In addition, a control sample was taken from the adjacent tap used for handwashing but connected to the same water supply. Water samples were taken from the tubing attachments, without prior cleaning, but following a 1 minute flush as currently recommended by the BDA. ${ }^{10}$ Each unit was sampled on two separate occasions during the working week. Following collection each specimen was placed in a coolbag with ice packs whilst transporting to the laboratory. Specimens were returned to the laboratory for processing within two hours of collection.

Samples were analysed for total viable counts (TVC) at $22^{\circ} \mathrm{C}$ and $37^{\circ} \mathrm{C}$ using a standard pour plate method. ${ }^{9}$ Briefly this comprised taking $1 \mathrm{ml}$ of the water sample and dispensing into 4 empty sterile $90 \mathrm{~mm}$ plastic petri dishes followed by the addition of $20 \mathrm{ml}$ of molten water agar to each plate and mixed well. The agar was allowed to set at room temperature. One set of plates are incubated at $22^{\circ} \mathrm{C}$ for 72 hours and the other set of plates at $37^{\circ} \mathrm{C}$ for 24 hours. Appropriate controls for each agar batch were assessed for sterility by pouring an agar plate with no sample for each time and temperature combination used. The colonies on each plate were counted immediately after incubation using an Anderman counter. The result (TVC) was expressed as the average number of colony forming units per ml of sample computed from the duplicate plates.

Practitioners were asked to complete a questionnaire whilst the first water sample was being collected.

\section{Statistical methods}

Colony counts at $22^{\circ} \mathrm{C}$ and $37^{\circ} \mathrm{C}$ for each specimen were entered into Minitab for Windows (v12.0). The microbial counts from each water outlet were compared using the Friedmans test. Suitable follow-up comparisons were then used to identify between which
Table 1 Microbiological quality of water from general dental practice units

\begin{tabular}{lccc}
\hline Source & $\mathrm{N}$ & Median CFU $/ \mathrm{ml} 22^{\circ} \mathrm{C}$ (range) & Median CFU $/ \mathrm{ml} 37^{\circ} \mathrm{C}$ (range) \\
\hline High speed handpiece & 40 & $2,475\left(51-1 \times 10^{5}\right)$ & $43\left(0-1 \times 10^{5}\right)$ \\
Triple syringe & 40 & $2,200\left(7-1 \times 10^{5}\right)$ & $2\left(0-1 \times 10^{5}\right)$ \\
Cup filler & 40 & $239\left(2-1 \times 10^{5}\right)$ & $1\left(0-1 \times 10^{5}\right)$ \\
Wash tap & 40 & $15\left(7-1 \times 10^{5}\right)$ & $1\left(0-1 \times 10^{5}\right)$
\end{tabular}

sources there were significant differences. The effect of disinfectants on microbial counts was examined using a Mann-Whitney test whilst the effect of age on the counts was examined using Kruskal-Wallis tests.

\section{RESULTS}

A total of 40 dental units were available for analysis from 39 different practices. The results of the microbiological investigation are shown in Table 1. Microbial contamination was highest from the high speed outlet followed by the triple syringe and cup filler. At both $22^{\circ} \mathrm{C}$ and $37^{\circ} \mathrm{C}$ there was evidence to suggest that the median TVC counts from the different sources were not all equal (both $\mathrm{p}<0.001$, Friedmans test). The results from the follow up comparisons indicated that at $37^{\circ} \mathrm{C}$, on average the TVC counts from the high speed water lines were significantly higher than those from the control tap water. At $22^{\circ} \mathrm{C}$ the TVC counts from the high speed lines, triple syringe and cup filler were all on average significantly higher than that from the control tap water. There were no further significant differences in the median TVC counts at either $37^{\circ} \mathrm{C}$ or $22^{\circ} \mathrm{C}$. The study included units from 11 different manufacturers (Figure 1). The small numbers of units from the large numbers of different manufacturers precluded a meaningful statistical analysis. The age of the units ranged from less than one year to greater than eight years (Figure 2). There was no evidence to suggest that the age of the unit had an influence on the microbi-

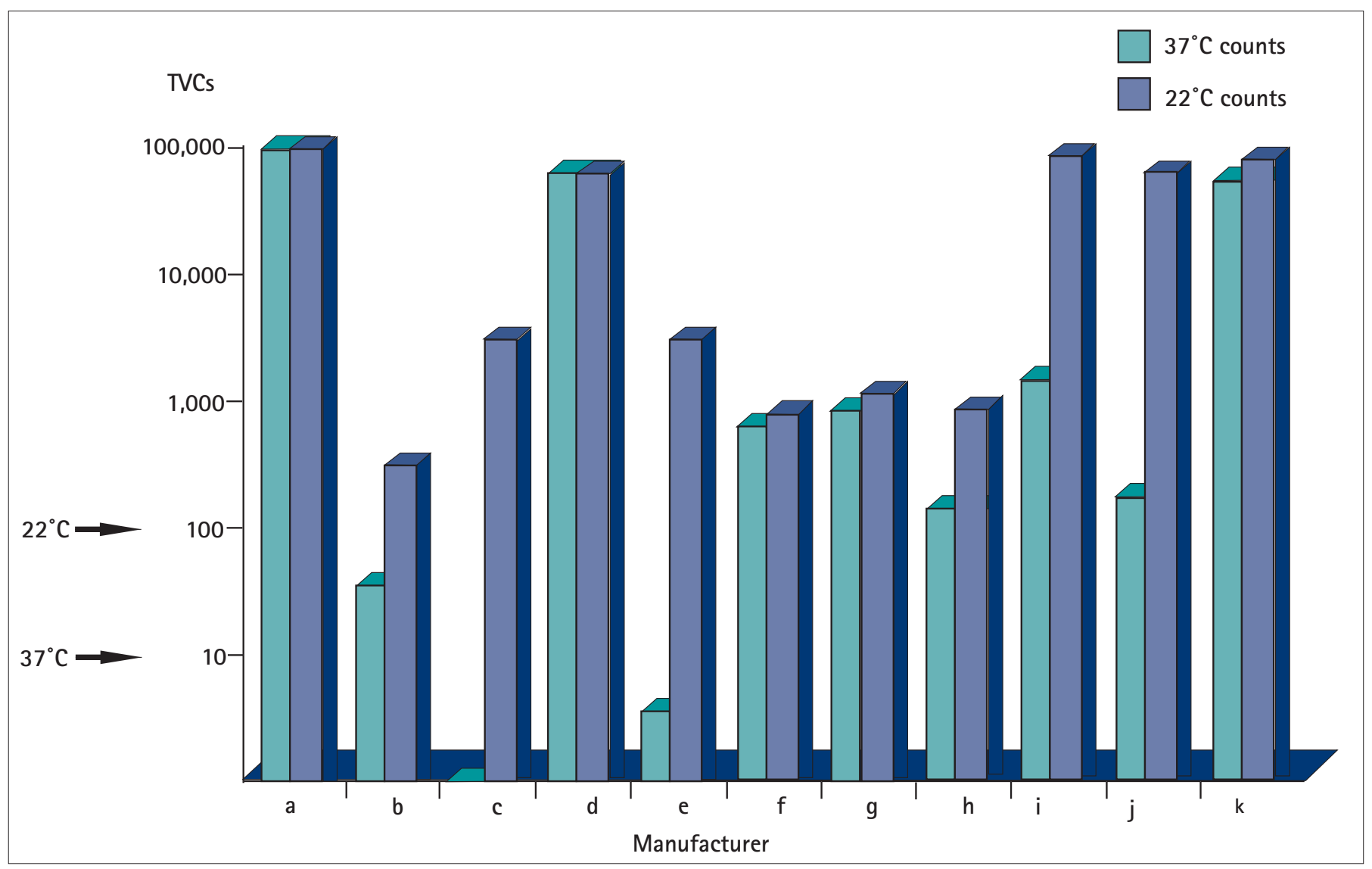

Figure 1 Median levels of microbial contamination from high speed outlets from different unit manufacturers (arrows indicate guideline values for potable water quality). 


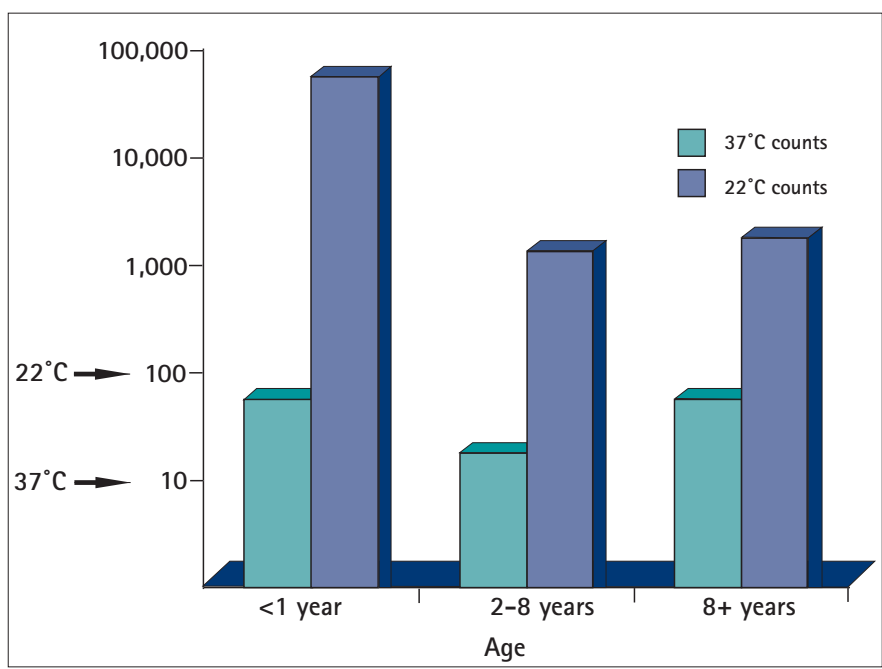

Figure 2 Median values of microbial contamination from high speed outlets from different ages of unit (arrows indicate guideline values for potable water quality).

ological quality of the water outlets analysed. There was a total of five units that were being disinfected with various chemicals but no significant differences were noted in the microbiological quality of water from the units (data not shown). Where disinfectants were used three respondents used an unspecified disinfectant, one used a 10\% Miltons solution and one used a dishwasher cleaning agent. Of interest was that only one practitioner in the survey claimed they had been supplied with a disinfection regimen by the dental unit manufacturer.

When questioned about flushing of dental unit water lines (Table 2) only one unit was performing the recommended flushing regimen (as suggested by the $\mathrm{BDA}^{10}$ ). Practitioners were also questioned on their choice of irrigant solution for surgical procedures (Table 3). Whilst some of the solutions used were suitable for surgical procedures a number were not of sufficient aseptic quality.

\section{DISCUSSION}

Whilst this work represents a small number of dental units, this study has confirmed and extended earlier work ${ }^{1-7}$ by demonstrating that the microbiological quality of water emerging from units in general dental practice does not conform to accepted guidelines for 'potable' water. The source of bacterial contamination within the dental unit water supply is thought to be due to

\begin{tabular}{lc}
\multicolumn{2}{l}{ Table 2 Frequency of flushing dental unit water lines } \\
\hline Frequency & Number \\
\hline Never flushed & 25 \\
Occasionally flushed & 2 \\
Monthly flush & 3 \\
Weekly & 5 \\
Daily & 2 \\
AM/PM sessions & 2 \\
Between each patient & 1
\end{tabular}

\begin{tabular}{l} 
Table 3 List of solutions used as irrigants for surgical procedures \\
\hline Sterile saline \\
Sterile water \\
Distilled water \\
Local anaesthetic solution \\
Corsodyl \\
Water from triple syringe \\
Sodium hypochlorite solution
\end{tabular}

proliferating bacteria, fungi and protozoa on the inner surface of the water lines, forming a biofilm. ${ }^{5}$ The significantly lower bacterial counts obtained from the water supplies to the wash hand basins in the same surgery lends support to this hypothesis. The higher bacterial counts found at $37^{\circ} \mathrm{C}$ from the high speed water lines supports earlier findings ${ }^{7}$ suggesting a large proportion of micro-organisms from this source may have been derived from aspiration of oral micro-organisms into the water lines.

There have been several attempts to reduce the microbial contamination of dental unit water lines including autoclaving of handpieces, handpiece replacement between patients, flushing of the unit prior to use, 'anti-contamination' devices to prevent retrograde aspiration of oral secretions into the water supply line, connection to a separate water supply (for example, connection to bottles of distilled water), chemical disinfection of waterlines, ultra-violet radiation disinfection and the use of in-line water filters. These have been developed and implemented in many dental practices ${ }^{3,10,14-16}$ with mixed long-term results and additional problems of blocked water lines produced by dislodged biofilm. The most commonly used procedure of flushing the handpiece with water prior to use may lower bacterial counts ${ }^{6,17}$ but high levels of microbial contamination can still persist $6,17,18$ as demonstrated in this study by the collection of samples after the recommended flush times. Furthermore, compliance with the recommended flushing schemes appears low from the subjects questioned in this study. This study also raised the issue of appropriate sterile solutions for irrigating exposed alveolar bone during surgical procedures. Sterile solutions such as sterile saline for irrigation are available and are recommended for surgical procedures.

We suspect that the complex design of dental chair equipment, resulting in the stagnation of water within the equipment lines where bacteria, including Legionella species could proliferate within a biofilm ${ }^{2}$ is a major factor affecting microbial contamination of water lines. The observation that a particular make of unit may have lower levels of contamination lends support to the hypothesis that the design of dental units may have an impact on the level of microbial colonisation. ${ }^{18}$ This would require further testing in a larger sample size. Of interest was the fact that all of the practitioners claimed that dental unit manufacturers had not provided them with any decontamination instructions. Dental chairs and units are considered to be medical devices and must therefore meet the relevant essential requirements of the Medical Devices Directive (93/42/EEC). In the UK the directive was implemented by the Medical Devices Regulations SI 1994 No 3017. The Medical Devices Regulations require that device manufacturers supply the necessary information to allow the safe use of their devices. This information includes cleaning, disinfection or sterilisation instructions as appropriate. It is also apparent from this study that, which ever method of decontamination is selected, it is particularly important to ensure it is applicable to a busy general practice setting where compliance with current schedules is poor.

\section{CONCLUSION}

We suspect that effective control of microbial contamination of dental unit waterlines resides in the engineering and design of dental units and attempts should be made to explore this option further, rather than resorting to the use of biocides. In the shortterm a reasonable protocol for disinfecting and monitoring the water supply in busy dental practices is urgently required, so that water used for dental patient treatment satisfies accepted safe public health standards.

We would like to acknowledge the technical assistance from the bacteriology staff at Glasgow Royal Infirmary for their invaluable help with the microbial assessment of the water samples. We would also like to acknowledge the kind help and support of the general dental practitioners who participated in this survey. 
1. Blake G C. The incidence and control of bacterial infection of dental units and ultrasonic scalers. BrDent J 1963; 115: 413-416.

2. Atlas R M, Williams J F, Huntington M K. Legionella contamination of dental unit waters. Appl Environ Microbiol 1995; 61: 1208-1213.

3. Pankhurst C L, Philpott-Howard J N. The microbiological quality of water in dental chair units. J Hosp Infect 1993; 23: 167-74.

4. Pankhurst C L, Philpott-Howard J N, Hewitt J, Casewell M W. The efficacy of chlorination and filtration in the control and eradication of Legionella from dental chair water systems. J Hosp Infect 1990; 16: 9-18.

5. Whitehouse R LS, Peters G, Lizotte J, Lilge C. Influence of biofilms on microbial contamination in dental unit water. J Dent 1991; 19: 290-295.

6. Williams H N, Kelley J, Folineo D, Williams G C, Hawley C L, Sibiski J. Assessing microbial contamination in clean water dental units and compliance with disinfection protocol. J Am Dent Assoc 1994; 125: 1205-1211.

7. Walker J T, Bradshaw D J, Bennett A M, Fulford M R, Martin M V, Marsh P D. Microbial biofilm formation and contamination of dental-unit water systems in general dental practice. ApplEnviron Micro 2000; 8: 3363-3367.

8. Williams H N, Paszko-Kolva C, Shahamat M, Palmer C, Pettis C, Kelley T. Molecular techniques reveal high prevalence of Legionella in dental units. J Am Dent Assoc
1996; 127: 1188-1193.

9. HMSO. The Microbiology of Water 1994. Part 1 - Drinking Water.

10. British Dental Association. Infection Control in Dentistry:Advice Sheet A12; 2000.

11. Centers for Disease Control. Recommended infection control practices for dentistry. MMWR Recomm Rep1993; 42: 1-12.

12. Paszko-Kovla C. Risk of infection from dental handpieces. ASM News 1991; 57: 287.

13. Martin M V. The significance of bacterial contamination of dental unit water systems. BrDent J 1987; 163: 152-154.

14. Scheid R C, Kim CK, Bright J S, Whitely M S, Rosen S. Reduction of microbes in handpieces by flushing before use. J Am Dent Assoc 1982; 105: 658-660.

15. Scheid R C, Rosen S, Beck F M. Reduction of CFU'S in high-speed handpiece water lines over time. Clin Prev Dent 1990; 12: 9-12.

16. Karpay R I, Puttaiah R, Mills S E, Plamondon T J, Dove S B, Levine U. Efficacy of flushing dental units for different time periods. J Dent Res 1997; 76: (abstract) 3366.

17. Gross A, Devine M J, Cutright D E. Microbial contamination of dental units and ultrasonic scalers. J Periodonto/ 1976; 47:670-673.

18. Challacombe S J, Fernandes L L. Detecting Legionella pneumophila in water systems: A comparison of various dental units. J Am Dent Assoc 1995; 126: 603-608. 19. HMSO . The Medical Devices Directive (93/42/EEC). Reference L169. 